\title{
Emotional Intelligence and Values in Digital World through Emoticons among Indian Students and Faculty
}

\author{
G. Bhuvaneswari 1* - $h$ htps://orcid.org/0000-0002-6666-6492, \\ Subhasri Vijayakumar 2 - $\mathrm{https://orcid.org/0000-0002-4949-5222}$ \\ 1,2Vellore Institute of Technology, Chennai, India \\ *e-mail: *bhuvaneswari.sb@gmail.com
}

Article Information
Received: November 11,2020

Accepted: November 27, 2020

Online: June 01, 2021

\begin{tabular}{l}
\hline \multicolumn{1}{c}{ Keywords } \\
\hline Emotional Intelligence, ESCI, Social \\
Awareness
\end{tabular}

\begin{abstract}
This study aims to striking differences between emotions in the real world, and emoticons of the digital world are the key focus areas as emotions play a crucial role in communication. It is undeniable that the emoticons of the digital world have changed altogether the way language is being perceived. This study also insists that while teaching time management and soft skills to students, it is vital to teaching digital communication (expressions via online). Therefore, it may need to be stressed in the curriculum. Conversation analysis or 'talk-in-interaction, a communication strategy, insists that everyday conversations have significance on the initiatorthe method using the Emotional and Social Competency Inventory (ESCI) to get the analysis done. The results confirm a significant relationship between emotional intelligence (particularly on the clusters of self-management, social awareness, and relationship management) and communication skills.
\end{abstract}

\section{INTRODUCTION}

It is an unquestionable fact that the modern digital world has reached its boom under the umbrella of technology that helps humans explore unreached territories within no time. Be it medical or engineering of humanities (NLP), technology, or any field, digital presence goes hand in hand with humans, starting from developing equipment to treating patients and constructing buildings and everywhere. It helps increase productivity, develop strategies, versatile working, learning opportunities, automation, and more. It does not allow unnecessary complications and helps one reach higher levels in any technology without much need to communicate to other humans; in other words, it helps us achieve accurate duplication in every field that humankind has ever touched. Technological advancements now take control of humans by not creating the need to be with other humans. Therefore, the term 'human' loses its primary meaning in the context of digital communication. One such example is the replica of communications, especially the expressions of emotions via online tools.

The emoticons of the digital world make humans forget the natural world and understand online communication in different perceptions altogether and lose the human touch in communication by applying conversation analysis in the digital communication context, primarily the nonverbal. The analysis of emoticons' expression and what exactly is meant by using it and how it understood in context by the reader examined in this paper. With emoticons, one communicates, directly and indirectly, has the power to handle hidden messages, play with one's mind, manipulate, practice hypocrisy, reflect one's image, and create self-image and a personality. These aspects are briefly detailed below. 


\section{Emoticons and Direct/Indirect Communications}

Emoticons have now become unavoidable body language expressions of the digital world. 'Face is the index of mind,' so goes the saying, and during online communication, it becomes highly beneficial for anyone who does not need to show his/her genuine expressions. More often than not, anyone can easily mislead another by using different emoticons and hiding the intended emotion of the person who communicates. The emoticons make one live in hyper-real situations all the time without having to bother about reality.

\section{Emoticons and Hypocrisy}

One can be subtle online and aggressive in real, sad online but happy offline, emotional online and robust in real, and the list goes on. 'Appearances deceive 'is the testimonial for digital hypocrisy, as it does not see any value of face to face communication. Whatever one expresses online need not be true. For example, a person may be crying while sending the message "I am fine," and one may never know about it unless seen directly.

\section{Self-reflection and Personality}

The term 'personality means mask in the original Latin word persona. Hippocrates from ancient Greece talks about personality traits in four dispositions, grumpy, melancholy, calm, and cheer. The present digital world does not differentiate between these four dispositions as the emoticons are not precise. The personality is unique and makes one stand out from the crowd. Therefore, there is a necessity to find out if it is true in the digital world. Digital communication defines one's personality, deviating from being misunderstood and expressed differently from actual. Personality is defined by what one communicates and does. While communicated online, the difficulty of assessing personality becomes complicated.

\section{LITERATURE REVIEW}

Successful behaviours of Individuals in academics and profession are factors of emotional

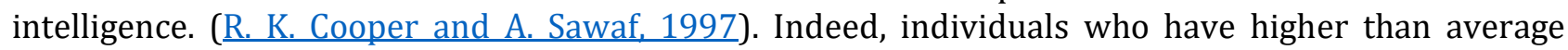
emotional intelligence demonstrate high levels of interpersonal skills. (Chermiss and Goleman (2001). Emotional intelligence is a multi-dimensional construct that connects emotions and cognition to improve individuals' interactions in their activities. (‥ Allam, 2011). Anger, happiness, fear, mood states, body states, and preferences influence the way people think, their decision-making skills, and various performance-based tasks (Forgas \& Moylan, 1987; Mayer \& Bremer, 1985; Salovey \& Birnbaum, 1989). The competencies and communication skills are measured by the emotional intelligence that he or she possesses. The General Intelligence quotient alone does not guarantee one's success. Psychologists have noted that general intelligence alone contributes to around 20 per cent of individual success in life, while the remaining 80 per cent comes from other factors such as emotional intelligence (Goleman, 1995). An individual's ability to express and comprehend emotions makes him or her emotionally unique and to communicate effectively. It is said that individuals possess some abilities to use emotions to enhance their thoughts effectively than others (Rastegar \& Karami, 2013).

Learning to stay with change, including it, and no longer being fearful of it is an undertaking for us all and involves no longer so many cognitive capabilities as appropriate feelings and attitudes. (Tim Sparrow Amanda Knight, 2006). Human beings are the success of acting with emotional talent boils down to an assertion that in most human beings, there is potentially suitable communication between the wondering intelligence (the prefrontal cortex) and the feeling brain (the limbic machine of the midbrain, such as the amygdala). Neuroscientist Candace Pert explores the brain-body verbal exchange systems, which advise that emotions do not occur simply in the intelligence as has been commonly believed until recently. Emotions now show up to be based on biochemical reactions throughout the body. They have been discovered in the coronary heart and the immune system as correctly as during the central nervous system. (Tim Sparrow Amanda Knight, 2006). Emotional intelligence is also associated with age. They determined an excellent correlation between tiers of emotional intelligence and the age of individuals. Mayer et al. (2000).

Kafetsios (2004) discovered sizeable variations in emotional intelligence and gender groups. Female participants scored higher than males regarding perceiving emotions and the experiential 
dimension (area) of emotional intelligence. Thus, gender has important outcomes on emotions and emotional intelligence. Women may also have a slight benefit in the complex capabilities of the emotional brain (Mayer et al., 1999). Skill in decoding nonverbal communication is viewed as an essential component of nonverbal ability. It is aligned closely with essential character characteristics, particularly empathy and being other-oriented (Losoya \& Eisenberg, 2001). Nonverbally sensitive persons may also be extra prone to emotional contagion effects, vicariously experiencing others' emotions ( Hatfield, Cacioppo, \& Rapson, 1994).

\section{Emotional Intelligence in Conversation Analysis}

Harvey Sacks are a pioneer in the field of conversation and discourse analysis. His theory says that talk-in-interactions are to be organized systematically. In the present digital world, where conversations have gone through a major revolution with the advent of more chat tools, use of smileys, emoticons, and more..., analysis of conversation will predominantly help to comprehend the mood, tone, and response of those who are conversing during their turns while talking, and how the expressions used via nonverbal communication takes control of the sequence of activities of the conversation. Austin (1962) argues "......that all utterances can be described as having three elements, which he called locution (the words that a sentence is made up of), illocution (the intended meaning that the speaker wishes to convey) and perlocution (the consequences or effect that the utterance has on its hearer)." This idea can be applied to how the non-verbal expressions are expressed in context and the meaning speaker intends to convey, the perlocution, the understanding of the opponent, and his response.

Conversing in a language is a form of social action. Everyday habitual conversations are mostly conditionally relevant. Conditionally relevant conversations are those in which 'hi-hi' greetings and 'how are you, 'I am fine' conversations are produced. There is a normative relationship between the dialogues in these kinds of conversations. It insists on producing the appropriate answer as 'I am fine' for a question like 'how are you.' It is common in digital communication as it stops taking the conversation to the next level. , In a face-to-face interaction, a person even if he says 'I am fine, based on his/her body language one can deduce if he/she is acceptable or not, and further conversations are built upon that, and there is no need for a defined normative behaviour in a real conversation.

Human communication has always been a topic of interest for linguists and language researchers. It is observed that language has a significant role in deciding one's reputation. There are multiple facesaving strategies practised in digital communication. Practising the art of polite communication while choosing the character and mood one wants to be in and using proper, polite emoticons without being caught could be a part of face-saving strategies. Furthermore, the right choice of words to express a balanced emotion is possible only in digital communication. Transition relevance is a significant part of group conversations and in a formal interview. The concept of the conversation is that once a speaker completes the dialogue, another speaker may turn the conversation to another level by picking up the thread line. However, in digital group conversations, one may not follow the transition due to a misunderstanding of the emoticons used and their perception of the signified meaning.

\section{Emoticons And Internet Based Communication}

Emotional Genius is the scholarly sources want through individuals to build other capabilities and competencies (Butcher \& Harvey, 1998). Dulewiez and Higgs (2000) emphasized the significance of managing thoughts as mechanisms in managing success in life. Academic overall performance success in life is associated with students' function in higher getting to know institution. Students have to prepare themselves after graduating to come into the job market. The query on how they will master the conversation and facts technology skills relies on their emotional intelligence degree in emotional intelligence. These necessary qualities should be considered to enhance communication and information science abilities, which can be related to self-consciousness, self-motivation, impulse control, humanistic capabilities, and temper administration. To belong to a particular group of any sort, the implicit price of membership is to agree not to notice one's feelings of uneasiness and misgivings and certainly not question anything that challenges the group's way of doing things. Emotions are unavoidable, and part of everyday life, and using online mode for communication shares the same role. Although computer-mediated theories say that online communication does not go hand in hand with 
face-to-face communication wherein one's emotions are studied and responded to. Still, the appropriate use of emoticons, receiving and perceiving the meanings of the intended communication proves the theory that non-verbal communication handles the central role of clear communication. 'While this was certainly true for mere text-based interactions, more recent forms of communication via the internet have adopted numerous additional features and incorporate several of these cues' (Antonijevic, 2008; Fullwood \& Orsolina, 2007).

\section{Non-Verbal Communication}

Non-verbal communication is supposed to have six functions in communication. When verbal communication does not support communication, non-verbal cues supplement verbal messages, emphasizing verbal messages to show the importance of the message, sometimes oppose verbal messages, restate the verbal information, and regulate verbal messages. One of the foundations of nonverbal communication depends on the individual's ability and uniqueness to deliver cues and signs of nonverbal communication. It focuses on how the message is encoded, decoded, and managed by an individual. People's ability varies in conveying non-verbal signals and messages, monitoring, and controlling non-verbal cues.

\section{METHODS}

The survey method is applied in this study. A questionnaire contains 25 different questions about emoticons usage via WhatsApp is taken. Sampling: Random sampling method was chosen, and a study using a questionnaire was done. One hundred thirteen individuals of age between 18-40 took part in the study. The Emotional and Social Competency Inventory (ESCI) was the basis for the questionnaire, and the responses received are as tabulated below.

\section{Charts and Analysis}

Table 1. Emotional and Social Competency Perception of People in Digital Communication

\begin{tabular}{llccc}
\hline ESCI Inventory & Description & Yes & No & Total \\
\hline Conflict management & $\begin{array}{l}\text { Hypocrisy has reached its peak in } \\
\text { the digital world due to the } \\
\text { expression via emoticons }\end{array}$ & 70 & 43 & 113 \\
Emotional awareness (self-awareness) & $\begin{array}{l}\text { I can understand peoples' feelings } \\
\text { through the emoticons they use. }\end{array}$ & 69 & 44 & 113 \\
Trust (Social-awareness) & $\begin{array}{l}\text { I can analyze and trust people } \\
\text { based on the Emoticons they use } \\
\text { I feel my communication is } \\
\text { effective because I have emoticons } \\
\text { Most often, emoticons have helped } \\
\text { me in handling embarrassing } \\
\text { situations }\end{array}$ & 65 & 48 & 113 \\
I feel that my vocabulary has & 62 & 51 & 113 \\
reduced because of emoticons & 66 & 47 & 113 \\
& $\begin{array}{l}\text { Emoticons have helped me build a } \\
\text { rapport with people }\end{array}$ & 74 & 39 & 113 \\
\hline
\end{tabular}




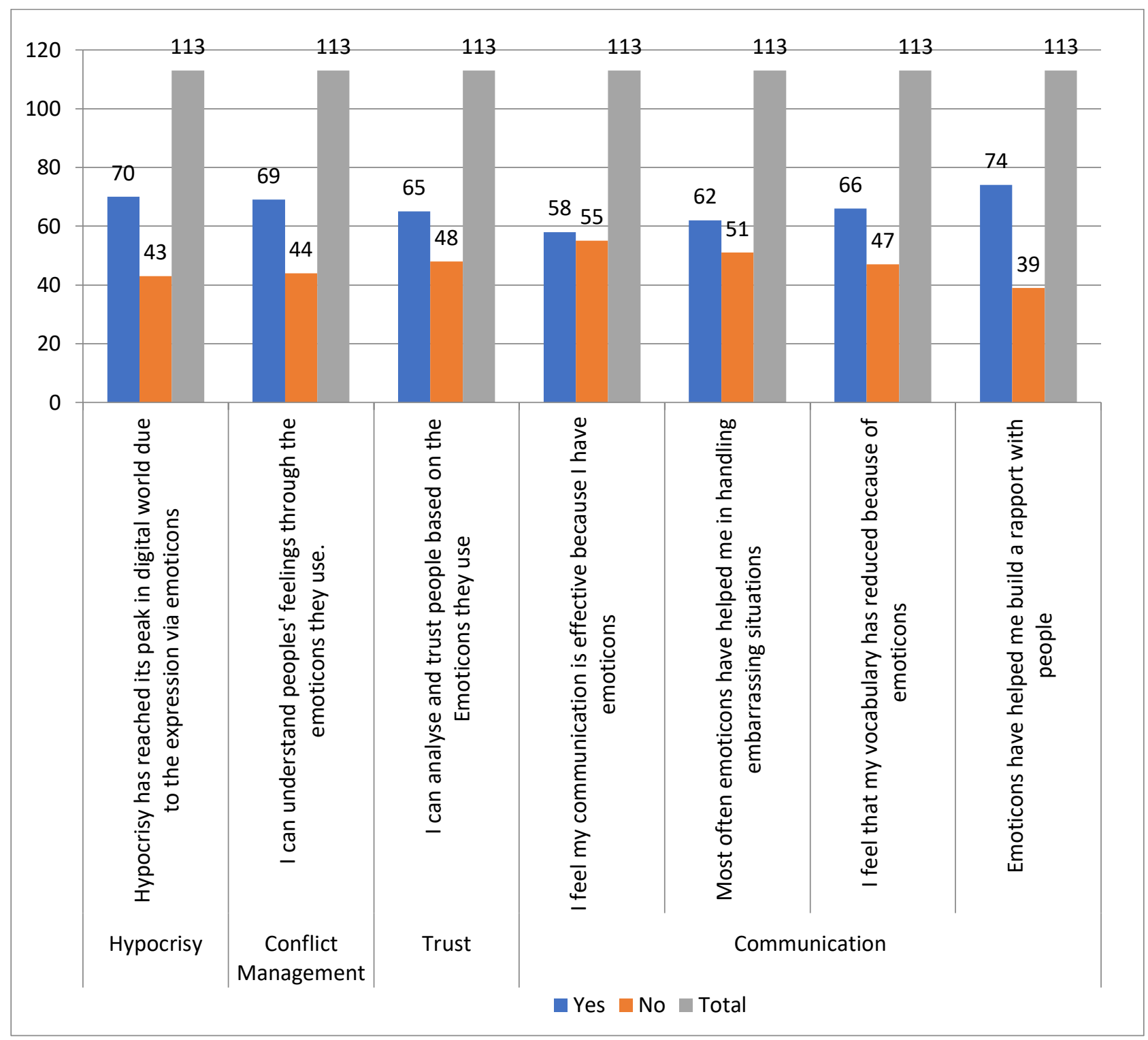

Fig 1: Emotional and Social Competency Perception of People in Digital Communication

\section{RESULTS AND DISCUSSIONS}

In his multi-dimensional mannequin of empathy, Davis $(1983,1994)$ conceptualizes one thing of other-oriented sensitivity as taking another's viewpoint or showing some empathic difficulty with others' emotional states. However, a distinct form of empathy is labelled "personal distress," suggesting emotional contagion effects. Taken to an extreme, nonverbal sensitivity can also purpose humans to experience some personal distress. It is vital to emphasize that when considering global skill or competence in nonverbal and emotional communication, an individual needs to decode, encode, and regulate conversation and emotional processes. Conflict management, emotional awareness, trust, and leadership styles are analyzed via this study. While non-verbal communication indicates a high level of understanding regarding managing conflicts, the participants' emotional awareness also has reached the highest frequency. The level of trust involved in understanding non-verbal cues and expression via emoticons did not significantly differ. Leadership styles of teachers had a moderate frequency level.

Table 2. Conflict Management Skills in Communication

\begin{tabular}{ccc}
\hline Level & Frequency & Percentage \\
\hline Low $(1.00-2.99)$ & 17 & 15.04
\end{tabular}




\begin{tabular}{lcc}
\hline \multicolumn{1}{c}{ Level } & Frequency & Percentage \\
\hline Moderate $(3.00-4.99)$ & 57 & 50.44 \\
High $(5.00-7.00)$ & 39 & 34.51 \\
Total & $\mathbf{1 1 3}$ & $\mathbf{1 0 0}$ \\
\hline
\end{tabular}

Mean $=5.17 \mathrm{Min}=3.73 \mathrm{Max}=6.78 \mathrm{SD}=0.67$

The results in Table 2 show the score of the overall composition of conflict management skills towards communication. It can be interpreted as most communicators showing a high understanding of conflict management (67.9\%). Moderately, the score is not any less in comprehending the communication towards conflict management. The overall mean value was 5.38 , indicating that communicators show a high level of positivity towards understanding conflicts.

Table 3. Emotional Awareness in Communication

\begin{tabular}{lcc}
\hline \multicolumn{1}{c}{ Level } & Frequency & Percentage \\
\hline Low $(1.00-2.99)$ & 21 & 18.58 \\
Moderate $(3.00-4.99)$ & 47 & 41.59 \\
High $(5.00-7.00)$ & 45 & 39.82 \\
\hline Total & $\mathbf{1 1 3}$ & $\mathbf{1 0 0}$ \\
\hline
\end{tabular}

Mean $=4.59 \mathrm{Min}=2.4 \mathrm{Max}=6.17 \mathrm{SD}=0.92$

The results in Table 3show the level of emotional awareness in communication wherein the minimum range was 2.30 while the maximum was 6.20 . The mean value was 4.59 for the total score, and according to the findings, it is noticed that the communicators followed their emotional intelligence and were aware of the emotions and cues in communication.

Table 4. Trust in Communication

\begin{tabular}{lcc}
\hline \multicolumn{1}{c}{ Level } & Frequency & Percentage \\
\hline Low $(1.00-2.99)$ & 33 & 29.20 \\
Moderate $(3.00-4.99)$ & 52 & 46.02 \\
High $(5.00-7.00)$ & 28 & 24.78 \\
\hline Total & $\mathbf{1 1 3}$ & $\mathbf{1 0 0}$ \\
\hline
\end{tabular}

Mean $=4.61 \mathrm{Min}=2.7 \mathrm{Max}=6.21 \mathrm{SD}=0.93$

Trust is the main factor in forming any professional relationship. The results in table 4 show that the mean value is 4.61 . There is a moderate frequency in trust as it involves many body language in person and direct communication.

Table 5. Overall Transactional Leadership Style Scores of Teachers

\begin{tabular}{lcc}
\hline Level & Frequency & Percentage \\
\hline Low $(1.00-2.99)$ & 17 & 15.04 \\
Moderate $(3.00-4.99)$ & 68 & 60.18 \\
High $(5.00-7.00)$ & 28 & 24.78 \\
\hline Total & $\mathbf{1 1 3}$ & $\mathbf{1 0 0}$ \\
\hline
\end{tabular}

Mean $=4.37$ Min $=2.3 \mathrm{Max}=6.14 \mathrm{SD}=0.91$

The results in Table 4 show a moderate frequency level in leadership style scores of the teachers. The mean is 4.37 that varies between 2.3 and 6.14. It can be garnered from the results that the overall emotional intelligence clusters and scopes meaningfully relate to work values such as Conflict Management, Emotional awareness, Trust in Communication, and Leadership Style. These results show that these work values lead to practice autonomy. It also leads to handling their own emotions and feels 
empathetic towards people around them while recognizing their roles about these set of values associated with their roles.

The overall understanding of these correlations is as per the following. First, visual recognizability has the impact of making the one all the more, for the most part, mindful of the presence of the other interactant, as reflected in expanded trust in confederate receptiveness and expanded worries about being assessed by the confederate. Second, this consideration regarding the other will have a diminished spotlight on the private self, restraining one's self-exposure and incredibly close self-revelations. Subsequently, one notices two elements of recognizability, a vital segment of the presence of trust, in this acquaintanceship circumstance. The first coming about because of the recognizability of the self to the next, which has a by and sizeable inhibitory impact upon self-exposure; the second coming about because of the recognizability of the other to oneself, which expands trust in the other.

\section{CONCLUSION}

From these findings, it is evident that non-verbal communication and emotional intelligence play a vital role in effective communication. Individuals with higher emotional intelligence were able to communicate well in workplaces. It is also observed that communicators were aware of the cues in communication and understood conflicts in digital communication. Thus, it can be construed that emoticons change the perception of the meaning of written communication, and individuals with higher emotional intelligence can use it to their advantage and communicate effectively. Although verbal exchange competencies are cutting-edge terms ( $\mathrm{Mc}$ Croskey, 1984), the records go way returned since communication competencies have been acknowledged thousands of years ago. The oldest book on verbal exchange skills can be retraced 5000 years ago, and its content material was once on the recommendation on how to speak effectively. In the generation of verbal exchange and records technology, know-how and know-how in managing information technology (IT) are priorities. Knowledge and ride in the use of computer systems are necessary aspects that influence an individual's future. The experience of handling computer systems and statistics science capabilities is essential for graduates who strive for professional excellence. Most jobs want graduates who can handle computer systems as information technology factors and align with the current wishes in the IT era. Therefore, employers put information technology as a necessary criterion in personnel determination and recruitment process. Communication and facts science competencies are part of the human capital variable wished for college students to survive in the job market after graduating. Muchhal (2014) careworn that the human capital variable consists of 4 components: collective capability, intellectual agility, attitude, and competence. These components form an excellent human capital variable criterion. Thus, Emotions play a vital role and act as an essential tool to have a successful life and career. In everyday life, Emotions influence and affect relationships with people around and also helps in creating one's own identity.

\section{Funding and Conflicts of Interest:}

The authors declare that there is no funding and conflicts of interest for this research.

\section{REFERENCES}

Abisamra, N. (2000). The relationship between emotional intelligence and academic achievement in eleventh graders. Retrieved from http://emotionalintelligence and academic achievement.html

Ahmad Marzuki, N., Mustaffa, C. S., Mat Saad, Z., Muda, S., Abdullah, S., \& Che Din, W. B. (2012). Emotional intelligence and demographic differences among students in public universities. Research Journal in Organizational Psychology \& Educational Studies, 1(2), 93-99.

Aravind, B. R., \& Rajasekaran, V. (2018). Advanced technological modality to explore ESL learners' vocabulary knowledge through social strategies. Journal of Advanced Research in Dynamical and Control Systems, $10(10), 250-256$.

Antonijevic, S. (2008). Expressing emotions online: an analysis of visual aspects of emoticon. Paper presented at the Annual Meeting of the International Communication Association, Sheraton 
New York, New York City. Austin, J. L. How to Do Things with Words. Oxford University Press. 1962. http://123.232.119.15:8888/auto/dbfile/91511 1682022 1682022.pdf

Butcher, D., \& Harvey, P. (1998). Meta-ability development: A new concept for career management. Career Development International, 3(2), 75-78. http://dx.doi.org/10.1108/13620439810207581

C. Cherniss and D. Goleman (2001) The Emotionally Intelligent Workplace, San Fransisco, JosseyBass, pp. 28-39. https://www.wiley.com/enus/The+Emotionally+Intelligent+Workplace $\% 3 \mathrm{~A}+\mathrm{How}+$ to + Select+For $\% 2 \mathrm{C}+$ Measure $\% 2$ C+and+Improve+Emotional+Intelligence+in+Individuals\%2C+Groups\%2C+and+Organiz ations-p-9780787961053

Davis, Mark. (1983). Measuring individual differences in empathy: Evidence for a multidimensional approach. Journal of personalilty and social psychology. 44. 113-126. http://dx.doi.org/10.1037/0022-3514.44.1.113

Davis, M. H. (1994). Social psychology series.Empathy: A social psychological approach. Westview Press. https://psycnet.apa.org/record/1993-98880-000

Dulewicz, V., \& Higgs, M. (2000). Emotional intelligence: A review and evaluation study. Journal of Managerial Psychology, 15(4), 341-372. https://www.emerald.com/insight/content/doi/10.1108/02683940010330993/full/ht $\underline{\mathrm{ml}}$

Elder, L. (1997). Critical thinking. The key to emotional intelligence. Journal of Developmental Education, 21(1), 40-42.

Forgas, J. P., \& Moylan, S. (1987). After the movies: Transient mood and social judgments. Personality and Social Psychology Bulletin, 13, 467-477

Fullwood, C. and Orsolina, I. M. (2007). Emoticons and impression formation. Applied Semiotics, $19,4-14$. https://www.researchgate.net/publication/303137750 Emoticons and Impression For mation

G. Bhuvaneswari, Manish Swami, P. Jayakumar. (2020). Online Classroom Pedagogy: Perspectives of Undergraduate Students towards Digital Learning. International Journal of Advanced Science and Technology, 29(04), 6680 - 6687. Retrieved from http://sersc.org/journals/index.php/IJAST/article/view/28069

Hatfield, E., Cacioppo, J. T., \& Rapson, R. L. (1994). Studies in emotion and social interaction.Emotional contagion. Cambridge University Press; Editions de la Maison des Sciences de l'Homme. https://psycnet.apa.org/record/1994-97007-000

Konstantinos Kafetsios, Attachment and emotional intelligence abilities across the life course, Personality and Individual Differences, Volume 37, Issue 1, 2004, Pages 129-145, ISSN 01918869, https://doi.org/10.1016/j.paid.2003.08.006.

Losoya, S. H., \& Eisenberg, N. (2001). Affective empathy. In J. A. Hall \& F. J. Bernieri (Eds.), The LEA series in personality and clinical psychology. Interpersonal sensitivity: Theory and measurement (p. 21-43). Lawrence Erlbaum Associates Publishers. https://psycnet.apa.org/record/2001-01720-002

M. Rokeach, (1973) The Nature of Human Values, New York: Free Press.

M. Ross, S. Schwartz, and S. Surkiss. (1999). Basic Individual Values, Work Values, and the Meaning of Work. [Online]. Available: http://www.choixdecarriere.com/pdf/6573/2010/RosSchwartzSurkiss1 999.pdf 
Mayer, J. D., \& Bremer, D. (1985). Assessing mood and affect-sensitive tasks. Journal of Personality Assessment, 49, 95-99.

https://www.tandfonline.com/doi/abs/10.1207/s15327752jpa4901 18

Mayer, John \& Roberts, Richard \& Barsade, Sigal. (2008). Human Abilities: Emotional Intelligence. Annual review of psychology. 59. 507-36.

https://doi.org/10.1146/annurev.psych.59.103006.093646

Mayer JD, Caruso DR, Salovey P. 1999. Emotional intelligence meets traditional standards for an intelligence. Intelligence 27:267-98. https://scholars.unh.edu/psych facpub/411/

McCroskey, J. (1984). The communication apprehension perspective. Beverly Hills, CA: Sage. http://www.jamescmccroskey.com/publications/bookchapters/003 1984 C1.pdf

Morreale, S. P., Spitzberg, B. H., \& Barge, J. K. (2001). Human communication motivation, knowledge and skills. Wadsworth: Thomson Learning. https://aclasites.files.wordpress.com/2017/02/sherwyn p- morreale brian hspitzberg_j- kevinbookfi-org-copy.pdf

Muchhal, D. S. (2014). A study of emotional intelligence and human capital variables. International Journal of Management Research, 2(2), 167-180. http://www.ijhssi.org/papers/v6(3)/version-I/G0603015054.pdf

Murphy, C.A., Coover, D., \& Owen, S. V. (1989) Development and validation of the computer selfefficacy scale. Educational and Psychological Measurement, 49, 893-899. http://dx.doi.org/10.1177/001316448904900412

Patil, A. S., \& Reimer, M. J. (2004). English and communication skills curriculum in engineer and technology course in the Indian State of Maharastra: Issues and recommendations. Global Journal of Engineering Education, 8(2), 209-218

R. K. Cooper and A. Sawaf (1997) Executive EQ: Emotional Intelligence in Leaders and Organizations, Grosset/Putnam, NY, 1997, pp. 67-79.

http://www.worldcat.org/title/executive-eq-emotional-intelligence-in-leadership-andorganizations/oclc/36178615

Rastegar, M., \& Karami, M. (2013). On the Relationships among Emotional Intelligence, Affective and Social Strategy Use, and Academic Achievement of Iranian EFL Learners. Theory and Practice in Language Studies, 3, 389-396. https://www.semanticscholar.org/paper/Onthe-Relationships-among-Emotional-Intelligence\%2C-RastegarKarami/ae4cf5a4f030c44e3eac62ac808ef046552bdc12

Rosenfeld, L. B., \& Berko, R. M. (1990). Communicating with competency, Instructor's manual and test bank. Glenview, Illinois: Scott Foresman.

https://www.researchgate.net/publication/277883174 Emotional Intelligence Its Rela tions To Communication and Information Technology Skills

Sacks, Harvey. (1995). Lectures on Conversation. Blackwell Publishing. ISBN 1-55786-705-4. http://www.lapetitedistribution.org/archive/Sacks Lectures-on-Conversation.pdf

Salovey, P., \& Birnbaum, D. (1989). Influence of mood on health-relevant cognitions. Journal of Personality and Social Psychology, 57, 539-551. https://psycnet.apa.org/record/1990$\underline{01950-001}$

Sparrow, Tim. \& Knight, Amanda. (2006). Applied EI : the importance of attitudes in developing emotional intelligence. Chichester: Jossey-Bass. https://www.wiley.com/enus/Applied+EI\%3A+The+Importance+of+Attitudes+in+Developing+Emotional+Intelligencep-9780470032732 
Stump, G. S., Husman, J., \& Corby, M. (2014). Engineering students' intelligence beliefs and learning. Journal of Engineering Education, 103(3), 369-387. http://dx.doi.org/10.1002/jee.20051

Subramanyam, K. (2012). Emotional intelligence. New Delhi: APH. http://www.ccsenet.org/journal/index.php/ass/article/download/45027/26262

Westmyer, S. A., DiCioccio, R. L., \& Rubin, R. B. (1998). Appropriateness and effectiveness of communication channels in competent interpersonal communication. Journal of Communication, 48(3), 27-48.http://dx.doi.org/10.1111/j.1460-2466.1998.tb02758.x

Z. Allam (2011) Emotional intelligence at the workplace: A psychological review Global Management Review, vol. 5, issue 2. 